African Journal of Teacher Education

ISSN 1916-7822. A Journal of Spread Corporation

Volume 10. No. 22021 Pages 78-95

\title{
Pre-Service Teachers' Perceptions of the Relevance of Teacher Professional Ethics in Contemporary Lesotho
}

\author{
Tebello Tlali \\ Orcid: http://orcid.org/0000-0003-1570-3369 \\ National University of Lesotho \\ tebello58@gmail.com.
}

\begin{abstract}
Previous research suggests that new teachers have more negative ethical perceptions than their senior counterparts. However, there is limited research on teachers' perceptions regarding the relevance of professional ethics in the contemporary world. Hence this study sought to explore the extent to which pre-service teachers in Lesotho consider professional ethics to be relevant. A qualitative approach was adopted and Kohlberg's (1987) moral development theory was used as the theoretical framework for the study. Data were generated with the use of both semi-structured and focus-group interviews. Forty-six (n 46) final-year Bachelor of Education (BEd) students were purposively selected to take part in this study. Sixteen (16) were interviewed individually, while 30 were interviewed in three focusgroups of ten participants each. The findings are that the participating pre-service teachers had mixed feelings about the relevance of professional ethics of teachers. Some emphasised the importance of a teachers' code of ethics while others indicated that some of the regulations were outdated. The position taken in this paper is that teacher professional ethics are timeless. These are meant to protect the interests of different stakeholders in education as well as the image of the teaching profession.
\end{abstract}

Key words: ethics; professional ethics; ethical responsibility; pre-service teachers; Kohlberg moral development theory

\section{Introduction and problem statement}

Teaching has been described as a noble profession (Bhusnar, 2018). According to Kahraman and Celik (2020), teachers are considered to hold an important role in societies. They are regarded as the key agents of education as well as the selfless role models for the learners 
(Genc, 2019; Sharma, 2020). Some scholars even describe teaching as a moral project or a moral craft (Maxwell \& Schwimmer, 2016; Al-Disi \& Rawadieh, 2019; Eren \& Soylemez, 2020). This signifies the magnitude of ethical responsibility ascribed to teachers. However, the issue of whether the teaching profession is as respectable as it ought to be remains dubious (Dimkpa, 2015). The status of the teaching profession has been scrutinised in previous research and the disregard for teacher professional ethics has increasingly become topical (Bhusnar, 2018; Kahraman \& Celik, 2020).

The misconduct attributed to some teachers in the Lesotho context has continually compromised the public perception of the teaching profession (Lesaoana, 2011). This remains a concern for the different stakeholders who wish to retain the integrity of this profession. The Lesotho's Ministry of Education and Training (MoET) acknowledges that without ethical teachers, most of its strategic goals would not be attainable. The Teaching Service Regulations (MoET, 2002) stipulates a range of misconducts teachers should refrain from. These include: (1) being convicted of any criminal offence involving moral turpitude; (2) using one's position as a teacher to further private or party political aims or to encourage disobedience or resistance to the laws of Lesotho; (2) conducting oneself improperly in official capacity or in any way that affects adversely one's performance of duties; (3) absence from duty without good cause; or (4) disclosure of the contents of any examination paper or providing answers to any person prior to or at an examination, or interference in any other manner with the conduct of examinations.

Irrespective of the provisions made in the Teaching Service Regulations (MoET, 2002) and Codes of Ethics (MoET, 2011), some teachers still infringe upon the regulations and continually get involved in unethical conduct such as absenteeism, examinations fraud, substance abuse and learner abuse. This view is further underscored by Lesaoana (2011, p. 8), who explains that "while there are teachers who fully abide by the rules and regulations of the teaching profession, there are also those who do not perform their duties effectively and efficiently". This lack of professionalism is a cause for concern for all stakeholders, especially the teacher training institutions (TTIs).

As one of the concerned TTIs, the National University of Lesotho (NUL), through the Faculty of Education, seeks to augment its programmes. The NUL's strategic goal is to produce ethically competent teachers who also exhibit commitment to their career (NUL, 2013). Pre-service teachers are expected to develop competence to differentiate between 
ethical and unethical behaviours, and act accordingly (Gelmez-Burakgazi \& Can, 2018). Conversely, it seems that graduates complete their teacher training with only a vague understanding of what is expected of them. Previous research suggests that new teachers have more negative ethical perceptions than their senior counterparts do (Gelmez-Burakgazi, Can \& Coskun, 2020). However, there is limited research on pre-service teachers' perceptions regarding the relevance of professional ethics in the contemporary world, hence the necessity to unearth any misconception with a view to mitigating them. Consequently, the current study sought to explore the perceptions of the Lesotho pre-service teachers in order to establish whether they perceive teacher professional ethics as relevant in the $21^{\text {st }}$ century or not. The study was therefore guided by the following objectives:

- To explore pre-service teachers' perceptions of the relevance of teacher professional ethics in the $21^{\text {st }}$ century

- To suggest mitigation strategies for any misconceptions that may be uncovered by the findings

\section{Theoretical Framework}

This study is anchored in Kohlberg's (1987) moral development theory as defined by Al-Disi and Rawadieh $(2019 ; 2020)$. Kohlberg developed a three-level model in which he describes the following stages of the ethical domain:

(1) The pre-conventional level: the individuals' sense of morality is controlled from outside the self. For example, a child is guided by the rules made by the authorities such as the parents and teachers.

(2) The conventional level: one's sense of morality is dependent on personal and social relationships. For example, a child continues to accept the authorities' rules while he/she has also developed an understanding that the rules are crucial in maintaining healthy relationships and societal order.

(3) The post-conventional level: one's sense of morality is defined in terms of mature and abstract principles and values. This level is regarded as the principled level of moral reasoning (Kretz, 2014; Kipper, 2017; Al-Disi \& Rawadieh, 2019; 2020).

According to Thoma (2014, p. 348), "Kohlberg's moral stages are described in terms of cognitive operations that directly describe the structure of moral thinking". While the NeoKohlberg movement sought to advance Kohlberg's original theory by adopting the notion of 
schemata development in defining the process of moral growth, the underlying supposition is the same, namely that ethical maturity is achieved through a dynamic and gradual process, spanning from childhood into adulthood (Han, Dawson, Thoma \& Glenn, 2019). This implies that an individual can progress through the different moral development stages due to their maturation of cognitive ability, as well as exposure to social, cultural, educational and religious influences (Kretz, 2014; Thoma, 2014; Chowdhury, 2016; Gelmez-Burakgazi \& Can, 2018; Ye \& Law, 2019; Chan \& Chen, 2020).

This theory provides a comprehensive framework for research on pre-service teacher ethical dispositions. Opportunities need to be created in order for pre-service teachers to introspect on their own ways of thinking, doing and being. This introspection creates a meaningful opportunity for them to recognise the complexity and multiplicity of the perks of the teaching career (Chapman, Forster \& Buchanan, 2013). While ethical dilemmas are bound to arise due to the morally rich sub-roles that exist within the relationships between teachers and the different stakeholders, teachers are expected always to uphold high moral standards (Sharma, 2020).

The guiding supposition of this study is that a matured ethical domain is prerequisite to becoming a teacher. Teachers are expected to operate at the post-conventional level of the ethical domain. They should also have the ability to apply the highest level of cognition and reflective practice (Kipper, 2017; Walters, Heilbronn \& Daly, 2017). Whenever teachers are confronted with moral dilemmas, they ought to retrieve knowledge from their ethical schemata to make spontaneous decisions about what is ethical or not (Al-Disi \& Rawadieh, 2019; Al-Disi \& Rawadie, 2020). This is more so in the fast paced $21^{\text {st }}$ century where teachers cannot afford to be sluggish in their moral decisions.

\section{Literature review}

For the purpose of this paper, the literature was reviewed on conceptualisation of ethics and professional ethics, the importance of teacher professional ethics and the place of teacher professional ethics in the $21^{\text {st }}$ century.

\section{Conceptualisation of ethics}

The concept ethics signifies the moral principles of a particular tradition, group or individual (Sultana, 2014). The etymology of the word 'ethics' can be traced to the Greek language. This word was derived from the Greek term ethos or ethikos, which stand for 'existence style', 'seeking a path of wise action', 'character', or general human moral dispositions (Sultana, 
2014; Chowdhury, 2016). The concept of ethics is also described as a sub-discipline of philosophy that focuses on the nature of morality (Sultana, 2014; Chowdhury, 2016). This sub-discipline is concerned with the prescription of norms and standards for human conduct. As an academic subject, ethics seeks to probe the reasoning behind human morality. Such philosophical scrutiny and exploration justifies individual moral choices and actions (Sultana, 2014; Chowdhury, 2016). The ancient philosopher, Aristotle, outlined human moral character in the terms: virtuous collection of appetites, desires, emotions and feelings for building an admirable character. Aristotelian character education is still relevant in teachers' professional ethics as it underscores self-discipline (Chowdhury, 2016).

\section{Professional ethics}

Ethics are universally accepted and are applicable both in personal and professional life (Sharma, 2020). Generally, ethics can be classified into two categories, namely theoretical ethics and applied ethics (Gulcan, 2015). Theoretical ethics comprise normative ethics, descriptive ethics and meta-ethics, while applied ethics refer to professional ethics (Abidin \& Zahrin, 2018). Normative ethics include the values and virtues that formulate the basis for judging whether the performed action is right or wrong. Descriptive ethics include human ethical beliefs, whereas meta-ethics explore the philosophical reasoning behind actions. Professional ethics, on the other hand, denote how ethics are applied in a particular professional milieu (McPherson, Forster \& Buchanan, 2019).

According to Sultana (2014), professional ethics denote a set of standards adopted by a particular professional community. These are regulated by standards often referred to as codes of ethics. A code of ethics is crucial, since it sets the boundaries within which a profession should operate (Sultana, 2014; Abidin \& Zahrin, 2018). In addition, Bhusnar (2018, p. 205) indicates that "professional ethics incorporate the individual, authoritative and corporate benchmarks of conduct expected of professionals". It needs to be clarified that there would be no profession without such ethical foundation (Abidin \& Zahrin, 2018).

\section{The importance of teacher professional ethics}

Ethical issues permeate every aspect of school life and they are always at play in all the teachers' actions. The complexity of the school environment places great demands on teachers to make countless spontaneous moral judgements in all their activities (Boon \& Maxwell, 2016; McPherson et al., 2019). An environment that nurtures positive learning hinges on ensuring harmonious co-existence among the various stakeholders, namely the 
learners, parents, colleagues and educational authorities (Boon \& Maxwell, 2016). It is therefore crucial to cultivate professional ethics as a cornerstone for providing a respectful, safe, warm, and friendly school context (Gelmez-Burakgazi, Can \& Coskun, 2020).

Marica (2013) typifies teachers' ethical role as two-pronged since it involves being both a moral agent and a moral trainer. This indicates that the teaching profession is undoubtedly charged with enormous ethical responsibility. As a result, those in this profession cannot afford to be found lacking in ethical competence and leadership (Marica, 2013; Bhusnar, 2018). Teachers are expected to uphold the highest ethical standards in their relationships, especially with the learners (Gelmez-Burakgazi et al., 2020). Teachers' conduct is obviously always under scrutiny. The society constantly makes judgements about teacher behaviour (Gluchmanova, 2017). At school as well as outside the school setting, teachers are seen as the embodiment of ethical standards such as integrity, care, trust, dress code and prudent societal relationships (Sultana, 2014; Dimkpa, 2015; Gelmez-Burakgazi \& Can, 2018; Devika \& Dilip, 2019).

Developing ethically intelligent teachers is fundamental since they are entrusted with relaying knowledge, skills and moral aptitudes to their learners. It is necessary to sensitize teachers about the ethical responsibility that comes with this profession. Pre-service teachers can be supported in various ways in their moral or ethical development (Chapman et al., 2013; Eren \& Soylemez, 2020). Firstly, pre-service teacher education should include obligatory courses in teacher professional ethics (Walters et al., 2017; Genc, 2019). Secondly, teacher ethics should be advanced through in-service programmes such as workshops around real-school-life ethical issues (Boon \& Maxwell, 2016). Thirdly, teachers can be guided and supported through ethical codes and regulations developed by various National Teaching Service commissions.

The aforementioned strategies play an important role in the ecology of professional self-regulation and they may protect the image of the teaching profession (Maxwell, 2017). The codes of ethics also seek to maintain recognition for this profession (Walters et al., 2017; Gelmez-Burakgazi \& Can, 2018). In this regard, the need to equip pre-service teachers with professional ethical codes and standards cannot be overemphasised (Gelmez-Burakgazi et al., 2020).

Teacher professional ethics in the $21^{\text {st }}$ century 
The 21st century is described in terms of globalisation, modernization and the fourth industrial revolution. Educational institutions ought to promote the $21^{\text {st }}$ century core competencies such as collaboration, digital literacy, critical thinking and problem solving as well as universal literacy (Dimkpa, 2015; Gluchmanova, 2015; Jan, 2017; Tican, 2018). In this milieu, teachers are expected to become change agents in advancing $21^{\text {st }}$ century knowledge and skills. Among other things they need to be well grounded in technology use (Dimkpa, 2015, Jan, 2017; Tican, 2018). Needless to say, life in the $21^{\text {st }}$ century is fast paced and so should be education. Teachers face new challenges that come with this era. As indicated by Gluchmanova, (2015, p. 120), "the new characteristics of the globalised world and its accelerated process of modernization have caused the society to face situations considered unthinkable". The question then remains: is there a place for teacher professional ethics even in the changing times?

Chowdhury (2016) highlights that in the past, religions had a prominent influence on society, and there were no questions about the importance of ethics. With the advent of modern science and technology, the societal and religious landscape shifted. Consequently, this has led to deterioration in moral education. Chowdhury (2016) indicates that the secular ideologies are becoming predominant in modern societies, and questions are being raised from individuals, groups and institutions about the legitimacy of character education. This position is further underscored by Sharma (2020), who observes that modern education is significantly different from the traditional one. Character development no longer has as much value, as it used to have in the tradition education system.

The realities of the fast paced $21^{\text {st }}$ century warrant humanity to revive its moral fibre. There are persistent concerns about the corrosion of the human morality and values in the postmodern society. As put by Marica (2013, p. 477), there is a perceived "moral crisis in today's world, [which include:] an education crisis, a family crisis, and a school crisis". Obviously, these crises individually and collectively contribute to an ongoing vicious circle of a global moral crisis. Thus, the collapse of the traditional family and society is correlated with the crisis in the schools and vice versa. Marica (2013) also indicates that even though there are no instant solutions to the global moral crises, the school can still serve as the mainstay for the restoration of morality.

\section{Research Design and Methodology}


The study is qualitative by nature, and it is situated within interpretivist paradigm. A descriptive research design (Cohen, Manion and Morrison, 2011) was adopted to explore the perceptions of pre-service teachers regarding the relevance of teacher professional ethics in the $21^{\text {st }}$ century. Descriptive designs also seek to understand the meaning or definitions that the participants have constructed. Cohen et al. (2011) add that the process through which meaning is attributed to a phenomenon can also be reflexive by nature, thereby compelling the participants to reflectively interrogate and redefine their own perceptions about a particular phenomenon.

Semi-structured and focus-group interviews were used to generate data. These methods are usually used together in qualitative research to enhance the richness of the findings. Semi-structured interviews, on the one hand, allowed for the collection of in-depth data. This style of interviewing also allowed probing for clarification of certain issues (Greeff, 2011). On the other hand, focus-group interviews were based on the assumption that group interaction would produce a wide range of responses, while at the same time allowing the pre-service teachers to freely give their views in a less intimidating platform (Cohen et al., 2011).

\section{Selection of Participants and Ethical Considerations}

The population of the study consisted of 162 final-year students in the Bachelor of Education (B. Ed) programme. This programme focuses on training the teachers for secondary and high school levels. Students are taught various pedagogical courses, such as (1) Introduction to Educational Foundations, (2) Critical Issues in Education, and (3) Philosophy of Education. While the topics related to teacher professional ethics are included in the above courses, they also permeate other courses offered in the programme. The final-year group was purposively selected, since it was considered to have accrued a comprehensive theoretical knowledge about these topics, as opposed to their junior counterparts.

The participants were requested to volunteer to take part in individual interviews and the number was not pre-determined. Sixteen (16) participants volunteered to be individually interviewed, using semi-structured interviews, while 30 participants were interviewed in three focus-groups of 10 participants each. Ultimately, a total of forty-six ( $n$ 46) participants were interviewed. The reason for following up semi-structured interviews with focus-groups was to supplement the data collected from individual interviews and to ensure crystallization of the data collection methods (Cohen et al., 2011). 
Ethical issues were observed by seeking permission from the relevant structures of the NUL, and informed consent was sought from the participants. None of the participants were coerced into taking part. It was also made clear that the participants were free to opt out if they so wished. Confidentiality and anonymity were observed by ensuring that none of the presented findings could be linked to any of the participants (Strydom, 2011). The participants were allocated pseudo-codes to disguise their identity. For instance, the 16 individual interview participants were labelled as II (Individual Interviews) A to P; whereas the focus-group participants were labelled on the basis of their respective groups as FG (Focus-group) FG1-A to J; FG2-A to $\mathrm{J}$ and FG3-A to J. All audio tapes and their transcriptions were safely locked away with the intention to destroy them after five years.

\section{Findings}

The interviews were transcribed verbatim and inductive codes were used to analyse the data (Merriam, 2009). Several issues emerged from the interviews with pre-service teachers on whether teacher professional ethics were still relevant in the $21^{\text {st }}$ century or not. Due to the intersecting themes, the findings from the semi-structured and focus-group interviews were synthesised and reported together in this section. The findings include the five constructs, namely (1) integrity of the teaching profession; (2) teachers as role models; (3) appearance and dress code; (4) social life; and (5) teacher-learner relationships.

\section{Integrity of the teaching profession}

The finding revealed several views about the relevance of teacher professional ethics in the $21^{\text {st }}$ century, especially in relation to the integrity of the profession. The participants made the following comments:

i. Lately teachers are losing their identity by hiding behind 'human rights'. They say they are free to do whatever they want. They overlook the fact that they could be breeching teacher professional ethics (II-B).

ii. Teachers' misconduct should be rebuked in order to maintain social respectability of this profession (II-D).

iii. A school is a place for learning and not for harbouring thugs. Teachers should familiarise themselves with the teaching service regulations so that they can be aware of what is expected of them (II-P). 
iv. Teacher professional ethics offer an excellent framework that stipulates the dos and don'ts within the education fraternity. However, some of the stipulations are too strict. They should relax a bit (FG1-A).

v. Lately learners are taught virtually. This means that teachers and learners do not interact physically. Therefore, there is no need to emphasise ethics (FG2-C).

vi. Teacher professional ethics provide a moral compass for teachers. Teachers need to protect their reputation so that they can be taken seriously (FG3-H).

vii. If prospective teachers feel like they are not able to abide by the rules, they should just leave the profession instead of ruining its reputation (FG3-J).

As can be seen from the foregoing findings, some participants asserted that teacher professional ethics have lost their value due to virtual teaching and learning. However, the majority of the participants felt that teacher professional ethics are still relevant, since they protect the integrity of the teaching profession and they also provide moral direction for teachers.

\section{Teachers as role models}

The participants had diverse views on the issue of whether teachers should be considered as role models for the learners or not. This is what they had to say:

i. $\quad$ Teachers are role models of their learners directly or indirectly. We must always model learner behaviour and lead by example (II-B).

ii. As teachers, we are role models to our learners; therefore, we should be mindful of whatever we do. We must practice what we preach (II-D).

iii. Teachers should keep integrity everywhere they go. I believe teacher behaviour has impacts on the learners (II-H).

iv. The issue of considering a teacher as a role model is totally insane. At the end of the day, the learners have their own choices regardless of all the efforts that teachers make in trying to act as role models (FG1-C).

v. This is a bit unfair and it's asking too much from teachers. It feels like imprisonment whereby teachers' moves are being monitored (FG2-E).

The above findings indicate that pre-service teachers have mixed feelings about being entrusted with the responsibility to become the learners' role models. Some of them felt that it was an honour whereas others felt that it was unfair and burdensome.

\section{Appearance and dress code}


The participants also deliberated on teachers' appearance and dress code; they put their views as follows:

i. Dress code is very vital for an ethical teacher. Teachers should have admirable dress sense, no tight and revealing clothes. Teachers should not dress like they are going to a club (II-A).

ii. Teachers should avoid dressing in the latest trends especially similar to their own learners. This is a big no! Embracing fashion is cool but teacher clothes should be age appropriate (II-B).

iii. The prescribed formal dress code helps us to avoid drawing the learners' attention to us hence destructing their concentration (II-D).

iv. I think the dress code is oppressive and backward. We are still young and dressing formally makes us look old (II-J).

v. These ethical codes are a nightmare. If I stay in this profession I will definitely end up losing myself. The formal dress code is just not my style (FG1-B).

vi. The issue of dress code causes a lot of discontentment since it restricts teachers to wear their stylish clothes. The kind of clothing prescribed for teachers can make us look too boring and old fashioned (FG2-F).

vii. Not all the rules need to change with times. So why should the teaching ethics change? Take an example of the nursing profession; nurses wear the uniform but they don't complain. Why are teachers complaining (FG3-B)?

The above views indicate that some pre-service teachers embrace the idea of a specific dress code. However, others are totally against the dress code prescription. They describe it as backward, old fashioned and oppressive.

\section{Social life}

Some views regarding how teachers ought to conduct their professional and personal lives also emerged. The participants voiced the following concerns:

i. Teachers' professional and personal lives have to be separated. It seems that the stakeholders are intrusive and inconsiderate that teachers are human too (II-N).

ii. Even though teachers are in the spotlight twenty-four seven, they still need to live their lives fully. If a teacher needs to go partying with friends, they should just go and have fun. Remember 'all work and no play makes Jack a dull boy' (FG1-E). 
iii. Whatever happens outside the school premises has got nothing to do with the school. This is the teachers' personal space and they should be given that freedom to do what they like, with no judgements (FG3-H).

iv. As a teacher, one feels that their right of freedom is being trotted down as every time they worry about who may be looking at what they are doing (FG3-J).

In the above findings, the participants expressed how unfair it was for society to intrude and monitor teachers' social and private life. They argued that teachers are human too.

\section{Teacher-learner relationships}

The participants also touched on the most controversial issue of whether or not teachers can have intimate relationships with the learners and the following opinions came up:

i. Teachers who have love affairs with the learners jeopardize the integrity of their profession. This creates an environment which is not conducive for learning because the teacher would have infringed on his or her professionalism (II-K).

ii. I vehemently condemn teacher-learner love affairs. Teachers use such affairs to their advantage. They should be abolished completely (II-O).

iii. Teacher-learner relationship should be allowed. As long as the learner is over the age of eighteen, I don't see any problem because someone who is over eighteen is an adult and can make informed decisions (FG1-C).

iv. Some of the learners are my age-mates if not older. So I can date them provided this does not affect the work environment (FG3-N).

From the above findings, it can be noted that some pre-service teachers differ in their views about whether or not teachers should have intimate relationships with the learners. There are those who feel that the codes of ethics are unfair, especially on young teachers.

\section{Discussion and recommendations}

The findings indicate varying opinions about whether or not teacher professional ethics are relevant in the $21^{\text {st }}$ century. Some participants say that teacher professional ethics have lost their significance due to the changing times and the use of virtual teaching and learning modes. Nevertheless, the majority emphasised that teacher professional ethics are relevant since they protect the integrity of the profession and provide moral direction for teachers. As indicated in the literature, codes of ethics are crucial in setting the boundaries within which teachers should operate (Sultana, 2014; Maxwell, 2017). It is important to preserve teacher 
professional ethics in order to build a solid foundation for teacher practices and conduct. As clarified in the literature, without such ethical foundation, the profession would continue to lose its recognition and value (Abidin \& Zahrin, 2018). Based on this position, it is recommended that teacher education providers and the concerned stakeholders should continue to reinforce the importance of the teaching professional ethics.

The participants expressed disparate feelings about being entrusted with the responsibility to become the learners' role models. While some thought that it was an honour to be seen in that light, others felt that it was too much to expect of them. As indicated in the literature, unlike other professions, being a teacher comes with enormous responsibility, namely that of being simultaneously a moral agent as well as a moral trainer. Hence the teachers have to be mindful of the moral images which they project through their own conduct (Marica, 2013). According to the literature, it is necessary to sensitize prospective teachers about the moral responsibility involved in the teaching profession, so that they can make informed choices (Chapman et al., 2013; Genc, 2019; Sharma, 2020; Eren \& Soylemez, 2020). The position held in this study is therefore that those seeking to pursue the teaching profession need to accept from the onset that being a role model comes as an indispensable part of the package. The different stakeholders should advance career guidance that enlightens prospective teachers about the perks of this profession.

Lately, some of the young upcoming teachers have been dissatisfied with the formal dress code that is recommended in this profession. Some describe it as backward, oldfashioned and oppressive. Others even confess that they might leave this career for fear of losing themselves due to the dull dress code. Nonetheless, there are still those who embrace the idea of dressing formally and being as presentable as possible. They are of the view that this will help them to project a respectable image of themselves. As indicated in the literature, teachers always have to reflect on their appearance and ask themselves: "is it befitting for a teacher to be dressed this way" (Sultana, 2014; Dimkpa, 2015). The most critical issue is that teachers spend most of their time with children or teenagers who are at their most impressionable age. Hence it is recommended that teachers should strive to look as decent as possible to avoid drawing the learners' attention away from the core business, namely the teaching and learning.

The participants also expressed how the teacher professional ethics infringe on their social and personal lives. They felt that this is unfair and the fact that they, too, are human is overlooked. It needs to be highlighted that whether one likes it or not, teacher conduct is 
always under scrutiny. As indicated in the literature, unlike other professions, the public always makes judgements about teachers' conduct (Gluchmanova, 2017). Teachers are seen as the epitome of ethical standards, both at school and outside. This also emanates from the fact that teachers are entrusted with the most impressionable minds of the learners. One way or the other, teachers' actions have a replicating effect on the learners. Hence, it is recommended that teachers should accept their public position and display ethical responsibility regardless of time and place (Marica, 2013, Bushnar, 2018).

While some participants felt that the codes of ethics were unfair, especially on young teachers, others appreciated the importance of these regulations, as far as inappropriate teachers-learner relationships are concerned. The MoET $(2002 ; 2011)$ stipulates that a teacher should maintain a professional relationship with learners and should not use their position to take advantage of the learners in any way. Accordingly, a teacher who gets involved in an intimate relationship with a learner commits a punishable misconduct. As indicated in the literature, such a teacher not only lacks integrity, but also brings the teaching profession into disrepute (Sultana, 2014). The position taken in this study is that there should be no excuses as far as teacher professional ethics are concerned. A teacher has to be mature enough to know what is right and what is wrong. It is important, therefore, for the different stakeholders to reinforce teacher professional ethics, with a view to protecting the learners and the image of the teaching profession (Walters et al., 2017; Gelmez-Burakgazi \& Can, 2018).

\section{Conclusion}

As explained in this paper, the $21^{\text {st }}$ century world faces serious moral degradation. A need for various stakeholders to take part in rebuilding societal moral fibre cannot be overemphasised. As postulated by Marica (2013), the moral collapse poses a great challenge for the school to serve as the mainstay for the restoration of morality. This calls for teachers to provide moral leadership. However, they will not be able to do so if they lack the requisite moral maturity and intelligence. As supported by the Kohlberg's (1987) moral development theory, the underlying assumption is that teachers ought to be ethically mature. They have to operate at the post-conventional level of the ethical domain. This is even more important in the fast paced $21^{\text {st }}$ century. Thus, teachers are required - now more than ever - to show ethical leadership and serve as the lifeline for societal ethical restoration.

\section{References}


Abidin, N.A.Z. \& Zahrin, Z. (2018). Students' perceptions of the influence of ethics education on their ethical environment and professional development. International Journal of Education, Psychology and Counseling, 3(7), 83-99.

Al-Disi, N.M. \& Rawadieh, S.M. (2019). Measuring Moral Judgment of Education Profession Ethics Among Pre-Service Teachers of the School of Educational Sciences at the University of Jordan. International Education Studies, 12(12), 7184.

Al-Disi, N. M. \& Rawadieh, S. M. (2020). Developing Education Profession Ethics Among Pre-services Teachers: Kohlberg Modeled Training Program Intervention. Journal of Education and Practice, 11(2), 38-47.

Boon, H.J. \& Maxwell, B. (2016). Ethics Education in Australian Preservice Teacher Programs: A Hidden Imperative. Australian Journal of Teacher Education, 41(5), 120.

Bhusnar, M.G. (2018). Conceptual Framework on Role and Importance of Professional Ethics among Teaching Professionals. Research Review International Journal of Multidisciplinary, 3(3), 204-208.

Chan, W.L. \& Chen, Y.W. (2020). Can higher education increase students' moral reasoning? The role of student engagement in the U.S. Journal of Moral Education. Advance online publication, doi: 10.1080/03057240.2020.1806045.

Chapman, A., Forster, D. \& Buchanan, R. (2013). The Moral Imagination in Pre-service Teachers' Ethical Reasoning. Australian Journal of Teacher Education, 38(5), 131143.

Chowdhury, M. (2016). Emphasizing Morals, Values, Ethics, and Character Education in Science Education and Science Teaching. The Malaysian Online Journal of Educational Science, 4(2), 1-16.

Cohen, L., Manion, L. \& Morrison, K. (2011). Research Methods in Education. $7^{\text {th }}$ ed. London and New York: Routledge Taylor and Francis.

Devika, R. \& Dilip, D. (2019). A study on professional ethics among school teachers with special reference to Coimbatore district. Research Explorer, VII(23), 8-12.

Dimkpa, D. (2015). Teachers' Conduct in the 21st Century: The Need for Enhancing Students' Academic Performance. Journal of Education and Practice, 6(36), 71-78. 
Eren, A, \& Soylemez. R. (2020). Pre-service teachers' professional commitment, sense of efficacy, and perceptions of unethical teacher behaviours. The Australian Educational Researcher. Advance online publication, doi: 10.1007/s13384-02000396-7.

Gelmez-Burakgazi, S. \& Can, I. (2018). Development and validation of a Professional Ethics Scale for pre-service teachers. Uluslararasi Egitim Programlari Dergisi, 8(2), 275298.

Gelmez-Burakgazi, S., Can, I. \& Coskun, M. (2020). Exploring Pre-Service Teachers' Perceptions about Professional Ethics in Teaching: Do Gender, Major, and Academic Achievement Matter. International Journal of Progressive Education, 16(4), 213-228.

Genc, S. (2019). Pre-service teachers' perceptions about teacher professional ethics course through metaphors. Journal of Education and Training Studies, 7(3), 150-160.

Gluchmanova, M. (2015). The importance of ethics in the teaching profession. ProcediaSocial and Behavioral Sciences, 176(0), 509-513.

Gluchmanova, M. (2017). Theoretical and practical aspects of a professional ethics of teaching. Human Affairs, 27(0), 75-81.

Greeff, M. (2011). Information Collecting: Interviewing. In A.S. de Vos, H. Strydom, C.B. Fouche, \& C.S.L. Delport (Eds.), Research at Grass Roots - From the Social Sciences and Human Service Professions, $4^{\text {th }}$ ed. (pp. 341-375). Pretoria: Van Schaik.

Han, H., Dawson, K.J., Thoma, S.J., \& Glenn, A.L. (2019). Developmental Level of Moral Judgment Influences Behavioral Patterns during Moral Decision-Making. The Journal of Experimental Education, 88(4), 1-36.

Jan, H. (2017). Teacher of 21st Century: Characteristics and Development. Research on Humanities and Social Sciences, 7(9), 50-54.

Kahraman, O. \& Celik, O.T. (2020). The Status of Teaching Profession from Teachers' Points of View. Educational Administration: Theory and Practice, 26(3), 519-564.

Kipper, K. (2017). A Neo-Kohlbergian approach to moral character: the moral reasoning of Alfred Herrhausen. Journal of Global Responsibility, 8(2), 196-211. 
Kohlberg, L. (1987) Philosophy of Moral Education. Translated by Wei, X.C. in 2000. Zhejiang Education Press, Hangzhou.

Kretz, L. (2014). Teaching Being Ethical. Teaching Ethics, 15(1), 151-172.

Lesaoana, N. (2011). Disciplinary Measures Adopted by Management Teams in Dealing with Teacher Misconduct in Maseru City Post Primary Schools. MEd dissertation. National University of Lesotho.

McPherson, A., Forster, D. \& Buchanan, R. (2019). Situated cases of ethical tensions when working with children and young people in educational contexts. Global Studies of Childhood, 9(2), 103-108.

Maxwell, B. \& Schwimmer, M. (2016). Professional ethics education for future teachers: A Narrative review of the scholarly writings. Journal of Moral Education, 45(3), 354371.

Maxwell, B. (2017). Codes of Professional Conduct and Ethics Education for Future Teachers. Philosophical Inquiry in Education, 24(4), 323-347.

MoET (Ministry of Education and Training). (2002). Teaching Service Regulations. Maseru: MoET.

MoET (Ministry of Education and Training). (2011). Codes of Good Practice. Maseru: MoET.

NUL (National University of Lesotho). (2013). Faculty of Education Strategic Plan: 20132018. Roma: NUL.

Sharma, C. (2020). Need of Ethical Values and Professional Ethics in Teaching Profession: A Study. International Journal of Multidisciplinary Educational Research, 9(6), 5256.

Sultana, M. (2014). Ethics in Teaching Profession. ABC Journal of Advanced Research, 3(1), 47-54.

Strydom, H. (2011). Ethical Aspects of Research in the Social Sciences and Human Service Professions. In A.S. de Vos, H. Strydom, C.B. Fouche and C.S.L. Delport (Eds.), Research at Grass Roots - From the Social Sciences and Human Service Professions (4 ${ }^{\text {th }}$ ed). (pp. 113-130). Pretoria: Van Schaik. 
Pre-Service Teachers' Perceptions of the Relevance of Teacher Professional Ethics in Contemporary Lesotho

Tican, C. \& Deniz, C. (2018). Pre-service Teachers' Opinions about the Use of 21st Century Learner and 21st Century Teacher Skills. European Journal of Educational Research, 8(1), 181-197.

Thoma, S.J. (2014). Measuring moral thinking from a neo-Kohlbergian perspective. Theory and Research in Education, 12(3), 347-365.

Walters, S., Heilbronn, R. \& Daly, C. (2017). Ethics education in initial teacher education: pre-service provision in England. Professional Development in Education, DOI: 10.1080/19415257.2017.1318773.

Ye, W. \& Law, W.W. (2019). Pre-service teachers' perceptions of teacher morality in China. Teaching and Teacher Education, 86(0), 1-13. 